\title{
Modernization of Mining Scheme in Developing Peat Deposit
}

\author{
Olga Puhova ${ }^{1}$, and Vladimir Lebedev ${ }^{1}$ \\ ${ }^{1}$ Tver State Technical University, A. Nikitin Street 22, 170026, Tver, Russia
}

\begin{abstract}
The article presents the results of the study of a peat deposit development scheme with improved spread parameters. The parameters are improved by forming the spread as moulded particles of a certain shape and size determined by the size of moulding machine grooves and the degree of peat relaxation. To obtain such particles a milling cutter is proposed to be replaced by a moulding mill at the stage of peat deposit milling. When excavated, the peat mass is loosened and fed into a roller moulding machine where the rollers, rotating in opposite directions, capture it and the peat is compressed. The loose structure changes into dense particle-particle packing. The circumferential speeds of roller rotations are equal. A trapezoidal groove profile is chosen for the moulded particles to leave it. The groove depth is $10 \mathrm{~mm}$. The uniformity of the moulded enlarged particle distribution over a drying field is characterized by a spread variation coefficient, which allows the spread quality to be evaluated. The enlarged particle spread is normalized by some cumulative actions characterizing the spread by parameters (the thickness, the average particle size, the size uniformity, the number of layers). Therefore, the drying of enlarged particles is intensified and peat yield per unit area is increased.
\end{abstract}

\section{Introduction}

Open-pit peat extraction depends on meteorological and natural conditions, therefore, the use of an improved technology [1-3,5] increases peat yield per unit area, which ultimately leads to an increase in a company's profit.

To study the ways of increasing peat yield, the technology of developing a peat deposit with improved spread parameters is selected. Peat has been extracted by milling for many years [4, 6-10]. Milling provides peat raw material as milling chips having the following disadvantages: the content of a large number of small dust-like fractions, heterogeneous fractional composition, small bulk mass, quality changes during long-term storage, for example, self-heating.

The fuel balance of areas [7, 11-13] consuming low-calorie fuels consists of milling peat, lump peat, and peat briquettes, the latter being in high demand among consumers as they can be used for automated house and social service heating. The technological scheme of peat milling requires modernization enabling the production of high quality and competitive products that are easy to use in a heating system with fuel supply and process control automation. 


\section{Materials and Methods}

The milling process [14-17] is one of the major ones in a milling scheme of peat extraction. The main requirement for its qualitative assessment is the duration of field drying. The spread parameters affecting significantly the internal mechanism of heat and mass transfer [18] and determining the intensity of moisture evaporation from a drying field surface are a particle size distribution, spread thickness and uniformity, a specific load value, a contact surface of particles with a deposit. The nature of the spread created by a milling machine has a significant influence on a peat drying process. To improve the nature, a milling cutter is proposed to be replaced by a moulding mill to obtain artificially moulded particles at the stage of peat deposit milling. When excavated, the peat mass is loosened and fed into a roller moulding machine where its rollers, rotating in opposite directions, capture the peat mass and the peat is compressed. The loose structure changes into dense particle-particle packing. The circumferential speeds of roller rotations are equal. A trapezoidal groove profile is chosen for the moulded particles to leave it. The groove depth is $10 \mathrm{~mm}$.

The number of drying layers is determined by the expression

$$
N=h_{\text {layer }} / h_{\text {part }}
$$

where $h_{\text {layer }}$ is a layer thickness; $h_{\text {part }}$ is a particle size in height, being chosen $1.2-1.5$ as optimal since the conveyor speed is consistent with the moulding speed and can be adjusted depending on specific conditions.

\section{Results}

Modernization of a technological scheme for peat extraction by milling can replace milling chips with enlarged trapezoidal particles of $10 \mathrm{~mm}$ high and $1.5 \mathrm{~mm}$ long. Enlarged particles formed in a roller milling machine (Fig. 1) are characterized by the size and uniformity determined by the size of the roller grooves and the degree of peat relaxation.

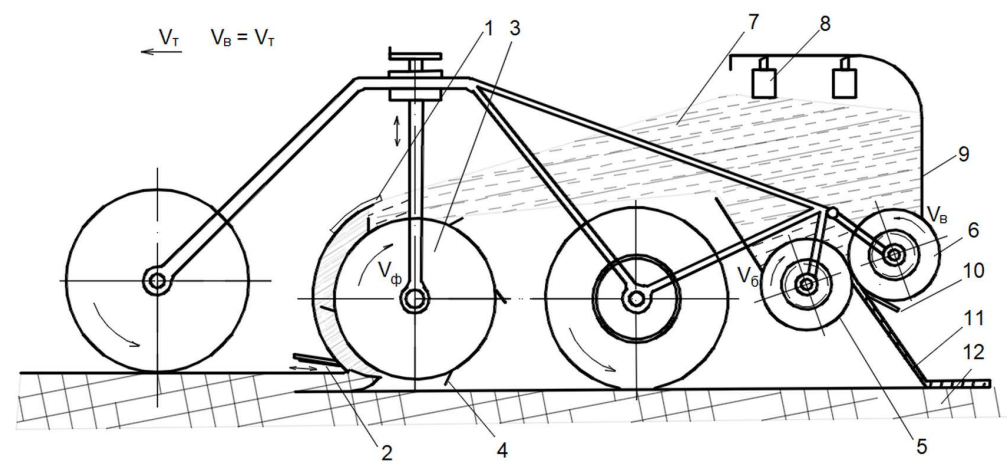

Fig. 1. A roller milling machine: 1 - guide casing, 2 - a jackknife, 3 - a cutter, 4 - a flat knife, 5, 6 working rollers, 7 - peat, 8 - load, 9 - a hopper, 10 - a puller, 11 - guides, 12 - a drying field.

The uniformity of moulded enlarged particle distribution over a drying field is determined by the spread variation coefficient assessing the moulded spread quality.

Table 1 shows the experimental data for determining the uniformity of enlarged particle spread. 
Table 1. The effect of moisture content and loading on particle uniformity.

\begin{tabular}{|c|c|c|c|}
\hline $\begin{array}{c}\text { Forming } \\
\text { moisture content, } \\
\text { \% }\end{array}$ & Loading, g & $\sigma$ & $\begin{array}{c}\text { Spread } \\
\text { uniformity, } \alpha\end{array}$ \\
\hline 80 & 751.2 & 133.6 & 0.178 \\
\hline 79.4 & 718.3 & 92.6 & 0.129 \\
\hline 77.1 & 677.1 & 94.5 & 0.139 \\
\hline 75.3 & 682.7 & 108.9 & 0.160 \\
\hline 74.1 & 648.9 & 160.0 & 0.247 \\
\hline 73.9 & 760.4 & 96.2 & 0.127 \\
\hline 71.8 & 354.7 & 45.0 & 0.127 \\
\hline 70 & 576.0 & 124.0 & 0.214 \\
\hline
\end{tabular}

The resulting indicator of the spread formation quality can be the number of enlarged particles formed on a certain area (Fig. 2).

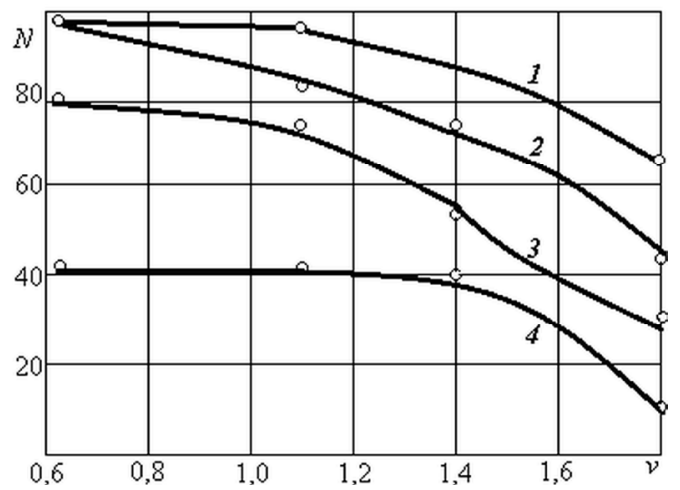

Fig. 2. The dependence of the number of particles $\mathrm{N}(\%)$ on the forming speed $v(\mathrm{~m} / \mathrm{s})$ and moisture content $\omega$ of the moulded mass: $1-84.5 \% ; 2-74.1 \% ; 3-72.6 \% ; 4-69.7 \%$.

The distribution of enlarged particles in a layer differs favorably from the distribution of milled peat particles. All (when arranged in a single layer) or most (when the number of layers is greater than one) of enlarged particles are exposed to direct solar radiation. The airflow flows around them from all sides. Our studies has shown that the particle-size distribution of the moulded enlarged particles improves (Fig. 3). The uniformity of the particle-size distribution intensifies the drying process of enlarged particles. 


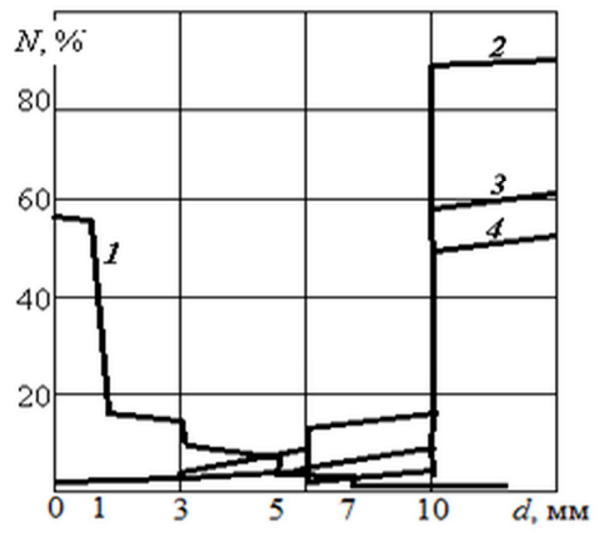

Fig. 3. The particle-size distribution of milling chips and enlarged particles moisture content of the moulded mass: $1-84.5 \% ; 2-74.1 \% ; 3-72.6 \% ; 4-69.7 \%$

The value of an average weighted diameter of the enlarged particles after moulding increases two- or threefold compared to the original milling chips. The size uniformity of particles increases. The spread has no small and dusty fractions. The particles of optimal size, which is more than $10 \mathrm{~mm}$, make up 70-90\% by weight. The improvement of the particlesize distribution of the enlarged particles can be explained by the design of a moulding machine as well as a peat property to maintain the shape given due to compression.

The peat adhesion to working body parts affects the design and operation mode and has a negative impact on particle moulding since in this case divergent normal forces tearing the moulded particle arise along the moulding planes. Thereby, the influence of peat moisture content and dispersion on its stickiness is determined (Fig. 4). It was established experimentally that the active mechanical impact of a conveyer on peat generates free associates when larger peat macroaggregates and aggregates break. The number of free functional groups of the associates is larger than that before dispersion.

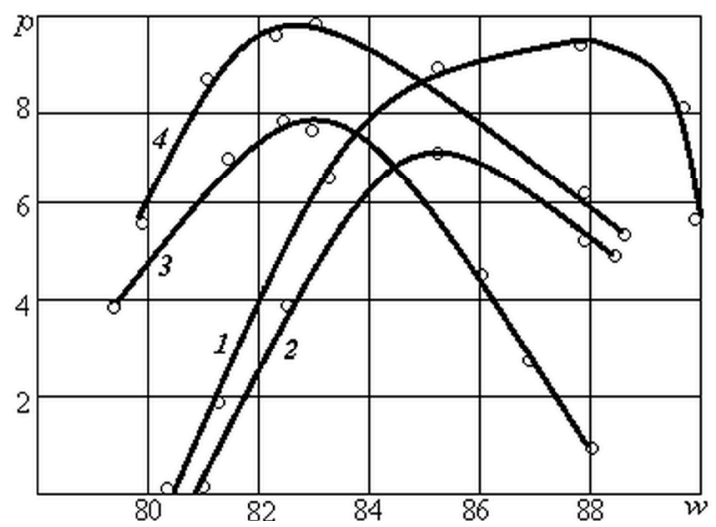

Fig. 4. The influence of moisture content and the degree of peat dispersion on its stickiness: $1-27,7$; $2-57,2 ; 3-70,8 ; 4-83,8 \%$

Table 2 presents the findings on the influence of a drying field area load and the moisture content of the moulding and bedding on the cyclic peat yield. 
Table 2. The effect of loading and moisture content on a cyclic peat yield

\begin{tabular}{|c|c|c|c|}
\hline $\begin{array}{c}\text { Moisture content } \\
\text { of enlarged } \\
\text { particles, \% }\end{array}$ & $\begin{array}{c}\text { Moisture content } \\
\text { of bedding, \% }\end{array}$ & $\begin{array}{c}\text { Loading of } \\
\text { drying field area, } \\
\mathbf{~ k g} / \mathbf{m}^{\mathbf{2}}\end{array}$ & Cyclic yield, t/ha \\
\hline 80.0 & 81.5 & 1.84 & 30.7 \\
\hline 79.4 & 80.0 & 1.88 & 31.4 \\
\hline 77.1 & 81.4 & 2.00 & 33.4 \\
\hline 75.3 & 79.0 & 1.64 & 27.4 \\
\hline 74.1 & 83.3 & 1.98 & 33.0 \\
\hline 73.9 & 79.0 & 2.22 & 37.6 \\
\hline 71.8 & 83.3 & 2.04 & 34.0 \\
\hline 70 & 79.5 & 1.95 & 32.6 \\
\hline
\end{tabular}

The cyclic yield for one layer spreading varies from 27.4 to $37.6 \mathrm{t} / \mathrm{ha}$. Loading a drying field area $\left(P_{d}\right)$ depends only on the moisture content of a moulded mass $(\omega)$ and is determined by the equation for highbog peat with a decomposition degree of $35 \% P_{d}=5.65-0.05 \omega \pm$ 0.039 .

Fluctuations in the loading value are due to uneven feeding of a roller milling hopper [19, 20], which is eliminated with the automatic control of filling [21-24]. The accuracy of steadystate modes and the quality of transient processes taken together determine the quality of an automatic system to control the moulding. The accuracy is assessed by the absence or presence of a mismatch in various steady-state modes and with the error ratio.

\section{Discussion}

Physical and mechanical properties of enlarged particles differ favourably from those of ordinary milling chips: the absence of small dust-like fractions, a homogeneous particle-size distribution, increased bulk mass, unchanged quality during long-term storage.

When the (smooth and ribbed) rollers come into contact, the peat mass experiences a complex stress state, which arises from the simultaneous action of vertical compression and horizontal shear. Due to the shear, the initial peat mass structure changes significantly. The particles are reoriented and displaced with their convergence relative to each other. The initial loose structure changes into dense particle-particle packing, the mass is compacted, and the bulk density increases. The compaction is accompanied by peat deformation determined by the amount of compression of the individual phases making up the system and the volumes of removed water and air.

The peat system compression occurs in two steps: first, there is a rapid decrease in volume due to the displacement of air into the atmosphere. Then the strain energy is accumulated as the energy of compressed air, which, given enough time, is dissolved in water or forced out through the pores. The existence of attractive forces between individual molecules leads to the appearance of similar forces between macrobodies, which surfaces converge to small distances, and, as a result, adhesion forces appear.

Stickiness is not detected at some minimum moisture content. With the moisture content 
increasing, the adhesion force increases too and reaches its maximum value. With the moisture content increasing further, the adhesion force decreases. The type of dependence is explained by the forces of moisture surface tension forming lateral menisci around individual contacts. With the moisture content increasing, the number of menisci grows faster than their radii of curvature. The adhesion force increases, and with further growth the individual menisci merge forming a liquid film and, as a result, adhesion decreases.

According to Table 1 the spread uniformity coefficient varies between $0.127-0.214$, with an average value being 0.15 , which is $3-4$ times less than that in the existing technological schemes for extracting milling chips. The spread uniformity in this case is provided by the design of a moulding machine, which is also a dosing one since the number of moulded particles per time unit strictly depends on the circumferential speed of moulding elements. Selecting the roller rotation speeds in accordance with the translational speed of an output conveyor can ensure a uniform distribution of particles over the area and their organized layering in any number of layers.

Fig. 2 shows that when the moisture content is close to the upper [17] plasticity limit of $84.5 \%$ (Fig. 2, Curve 1), the number of moulded particles retained their shape in the spread depends on the moulding speed and makes $100 \%$ up to the speed of $1.1 \mathrm{~m} / \mathrm{s}$. Then their number decreases to $63 \%$ with the speed increase. Keeping the moulding moisture content close to the lower limit of plasticity reduces the number of moulded particles and those retained their shape in the spread up to $63 \%$. This is explained by the deterioration of air evacuation conditions due to the formation of additional air-conducting pores. The addition of dry crumbs up to $30 \%$ (Fig. 2, Curves 3 and 4) does not have a negative impact on the spread nature.

The studies have shown that the increase in peat dispersion affects the maximum stickness values moving towards lower moisture contents. This can be explained by increasing capillary forces in comparison with peat of lower dispersion since the adhesion is detected in peat having a plastic type of consistency characterized by capillary phenomena that manifest themselves under the action of external solution menisci at the boundary with the gas phase. The increase in the absolute value of stickiness is caused by the decrease in the number of contacts and the forces of molecular interaction due to increased particle packing. The final state of the treatment process is characterized by the fact that the bigger the total pan accumulation is, the bigger is the accumulation of particles in the fine-dispersed area. When the accumulations of less than 250 micron fractions are similar, that of fine-dispersed fractions is higher if the available total is bigger. That is why the rate of fine-dispersed fraction accumulation is proportional to the rate of pan (less than 250 microns) accumulation and the available total of fine-dispersed fractions.

The amount of stickiness (Fig. 4) and its maximum value depend on the cleanliness of groove surface treatment affected by the groove depth and the radius of embedded irregularity rounding. The compaction load affects the stickiness value only for peat of a low degree of dispersion with $27.7 \%$ of particles being less than 250 microns since deep plastic deformations do not make the stickiness depend on the pressure applied to the sample.

All this contributes to the intensification of a drying process in the technology of peat deposit development with improved spread parameters. The spread nature, i.e. its thickness, size and number of moulded particles, their distribution on the drying field, the number of layers, depend on many factors, but, first of all, on the physical and mechanical properties of the moulded peat mass and the speed parameters of the machine.

\section{Conclusion}

Modernization of the technological scheme for peat extraction by milling provides the replacement of milling chips with enlarged trapezoidal particles, with the quality of a finished 
product as well as the functionality of process control improving.

The production of enlarged particles in a roller moulding machine is accompanied by complex physical processes: compression with a lateral shift in moulding machine grooves and subsequent elastic expansion of the particles on a drying field. Peat compaction occurs due to removing and compressing the air phase. The permissible moulding speed $(1.4 \mathrm{~m} / \mathrm{s})$ for obtaining a high-quality spread and production depends on the properties of original peat (moisture content and dispersion) as well as on peat adhesion to metal roller surfaces.

The studies have shown that peat adhesion with the metal surfaces of a milling cutter working body depends not only on peat moisture content and dispersion, but also on the moulding speed. Therefore, the ratio of the amount of peat stuck on a smooth roller of a working machine to the peat weight expressed as a percentage is not constant and depends on the degree of peat dispersion and moisture content, and increasing the moulding speed reduces the peat adhesion. The mechanical treatment of peat does not only change its structural-mechanical but physical-chemical properties. The value of total moisture capacity can be used as one of the basic indicators determining the combination of various characteristics of raw peat and finished products.

Thus, the study of the milling technology of peat deposit development shows that it can be improved by the spread parameters. They are significantly better than the similar ones for a milling peat layer: the coefficient of field load variation has decreased from 0.5 to 0.1 ; the average weighted particle diameter has increased by 2.5 times; and the content of optimal size fractions has increased to $70 \%$. The addition of dry crumbs up to $30 \%$ during peat harvesting has not negatively affected the spread nature. It has contributed to the intensification of drying enlarged particles and, therefore, the increase in the cyclic peat yield.

\section{References}

1. O. Misnikov, Mires and Peat, 18, 22, 1-15, (2016)

2. O. Misnikov, Mires and Peat, 21, 7, 1-14, (2018)

3. B.F. Zyuzin, O. Misnikov, V.V. Panov, L.V. Kopenkina, Gornyi Zhurnal, 5, 73-76, (2013)

4. E.A. Kremcheev, A.S.Danilov, Yu.D., Smirnov Journal of Mining Institute, 235, 96105 ,

5. O. Misnikov, A. Timofeev, O. Pukhova Polymer Science. Series D, 8, 1, 66-74, (2015)

6. O.S. Misnikov, I.O. Korolev, Polymer Science. Series D, 10(3), 255-259, (2017)

7. O.S. Misnikov, E.Yu. Chertkova, Eurasian Mining. Gornyi Zhurnal, 1 (21), 63-68, (2014)

8. O. Misnikov, E3S Web of Conferences, 105, 01010 (2019)

9. O. Misnikov, V. Ivanovm E3S Web of Conferences, 15, 01017 (2017)

10. O.S. Misnikov, O.V. Dmitriev, E.Yu. Chertkova, Eurasian Mining. Gornyi Zhurnal, 2 (24), 30-34 (2015)

11. O. Misnikov, E3S Web of Conferences, 21, 01020 (2017)

12. O. Misnikov, Polymer Science. Series D, 7(3), 252-259, (2014)

13. S.N. Gamayunov, O.S. Misnikov, Inzhenerno-Fizicheskii Zhurnal (IFZh), 71(2), 233234 (1998)

14. A.E. Afanas'iev, S.N. Gamayunov O.S. Misnikov, Colloid Journal: Kolloidnyi Zhurnal, 61(3), 274-279, (1999)

15. O.S. Misikov. Journal of Physics, 1384, 012031 (2019) 
16. O.S. Misnikov, A.E. Afanas'iev, Theoretical Foundations of Chemical Engineering, 37(6), 582-589 (2003)

17. O.S. Misnikov, O.V. Dmitriev, V.I. Popov, E.Yu. Chertkova, Polymer Science. Series D, 9(1), 133-139 (2016)

18. Kremcheev E.A., Kremcheeva D.A., Journal of Industrial Pollution Control, 33(1), 787791 (2017)

19. O. Misnikov, A. Timofeev, O. Pukhova, Polymer Science. Series D, 8(1), 66-74 (2015)

20. Abu-Abed F.N., Martynov D.V., Ivanova A.V., Dopira R.V., Kordyukov R.Y., Journal of Engineering and Applied Sciences, 11(16), 9636-9645 (2016)

21. O. Misnikov E3S Web of Conferences, 41, 01046 (2018)

22. Lebedev V., Puhova O., E3S Web of Conferences, 105, 01006 (2019)

23. Matveev Y.N., Palyukh B.V., Stukalova N.A., Bogatikov V.N. IJAER, 10(24), 4571745723 (2015) 